\title{
Anti-NMDA receptor encephalitis and nonencephalitic HSV-1 infection
}

Amy Salovin, MS, Jason Glanzman, Kylie Roslin, Thais Armangue, MD, PhD, David R. Lynch, MD, PhD, and Jessica A. Panzer, MD, PhD

Neurol Neuroimmunol Neuroinflamm 2018;5:e458. doi:10.1212/NXI.0000000000000458

\section{Abstract}

\section{Objective}

To determine whether there is an association between nonencephalitic herpes simplex virus 1 (HSV-1) infection and anti-NMDA receptor encephalitis (anti-NMDARE).

\section{Methods}

Antibody testing was performed using samples from 2 cohorts in a case-control observational study. The cohort "Philadelphia" included 16 serum samples of pediatric anti-NMDARE cases and 42 age-matched controls with other neuroinflammatory disorders studied at the Children's Hospital of Philadelphia and University of Pennsylvania. The cohort "Barcelona" contained 23 anti-NMDARE patient samples and 26 age-matched participants with other neuroinflammatory disorders studied at IDIBAPS-Hospital Clinic, University of Barcelona. The presence of HSV-1 IgG antibodies was examined by ELISA. As an additional control, IgG antibodies to cytomegalovirus (CMV) and Epstein-Barr virus viral capsid antigen (EBV-VCA) were determined.

\section{Results}

In each cohort, more participants with anti-NMDARE than controls had anti-HSV-1 IgG antibodies. In the Philadelphia cohort (58 participants), 44\% of anti-NMDARE cases had antibodies to HSV-1 compared with $14 \%$ controls (OR 4.67, 95\% CI 1.3-17.3, $p=0.031$ ). In the Barcelona cohort (49 participants), 52\% of participants with anti-NMDARE had antibodies to HSV-1 compared with $31 \%$ of controls (OR 2.45, 95\% CI 0.7-7.9, $p=0.155$ ). Overall, $49 \%$ of anti-NMDARE cases have antibodies to HSV-1 in these 2 combined cohorts compared with $21 \%$ of controls (Mantel-Haenszel OR 3.21, 95\% CI 1.3-7.7, $p=0.007$ ).

\section{Conclusion}

Past HSV-1 infection was found in significantly more anti-NMDARE cases than controls. This suggests a meaningful association between nonencephalitic HSV-1 infection and development of anti-NMDARE.
Correspondence

Dr. Lynch

lynchd@pennmedicine.upenn.edu 


\section{Glossary}

CHOP = Children's Hospital of Philadelphia; CMV = cytomegalovirus; EBV = Epstein-Barr virus; HSV = herpes simplex virus 1; NMDAR = NMDA receptor; NMDARE = NMDA receptor encephalitis; UPenn $=$ University of Pennsylvania.

Anti-NMDA receptor encephalitis (anti-NMDARE) is a recently described autoimmune encephalitis associated with psychosis, seizures, dyskinesias, hypoventilation, and autonomic instability, attributed to antibodies against the GluN1 subunit of the NMDA receptor (NMDAR). ${ }^{1}$ This disorder is now the most commonly identified nonviral cause of encephalitis. ${ }^{2}$ In approximately $50 \%$ of teenage girls and adult women with the disorder, it is triggered by an NMDARexpressing ovarian teratoma. ${ }^{3}$ By contrast, greater than $90 \%$ of young girls or males with the disorder have no identified trigger, although it may be associated with viral infection. ${ }^{4}$ Approximately $10 \%-25 \%$ of patients with herpes simplex virus 1 (HSV-1) encephalitis have an immune-mediated relapse associated with GluN1-specific antibodies and antiNMDARE symptoms. ${ }^{4,5}$ The association of nonencephalitic HSV-1 infection with anti-NMDARE has not been examined. To investigate the possibility that nonencephalitic HSV-1 infection could trigger the production of anti-NMDAR antibodies, this study examined HSV-1 seropositivity in 2 participant cohorts, with and without anti-NMDAR encephalitis, to ascertain if an association exists between nonencephalitic HSV-1 infection and anti-NMDARE.

\section{Methods}

\section{Participant material}

Cases were identified by neurologist diagnosis following review of clinical information (table) combined with results of anti-NMDAR antibody testing from serum sent to neuroimmune repositories at the Hospital of the University of Pennsylvania, the Children's Hospital of Philadelphia, or University of Barcelona. Sera from the Children's Hospital of Philadelphia (CHOP) and University of Pennsylvania (UPenn) repositories were combined into 1 cohort (Philadelphia). Sera from the University of Barcelona were analyzed as a separate cohort (Barcelona). We identified case sera from children aged $0-11$ years deposited in the Philadelphia repositories between 2008 and 2011 and from children aged 0-17 years submitted between 2008 and 2017 in the University of Barcelona repository. Children with a known tumor or with IV immunoglobulin treatment before sample collection were excluded. We identified 39 combined cases fulfilling these criteria, 16 from the Philadelphia cohort and 23 from the University of Barcelona. The mean age of the combined cohorts was $9.0 \pm 4.7$ years (range $1-17$ years). The Philadelphia cohort contained children with a mean age of $6.8 \pm 3.1$ years, and the Barcelona cohort contained children with a mean age of $10.6 \pm 5.0$. To limit sampling bias, 68 age-matched controls with other potential neuroimmune disease were identified from the same repositories. From
Philadelphia, 43 controls were identified, and 1 was seropositive for HSV2 IgG and was excluded. Included controls had a mean age of $7.9 \pm 2.4$ years. From the University of Barcelona, 26 controls were identified with a mean age of $10.5 \pm 5.2$ years. No participants had known HSV encephalitis.

\section{Standard protocol approvals, registrations, and patient consents}

Samples were collected in accordance with the guidelines of Institutional Review Boards of the CHOP, UPenn, and University of Barcelona. Informed consent was obtained from each participant.

\section{ELISA analysis}

The following commercially available solid-phase ELISA kits were used according to the manufacturer's instructions: HSV-1 IgG (20-HSGHU-E01, ALPCO and ab108737, Abcam), HSV2 IgG (20-H2GHU-E01, ALPCO and ab108739, Abcam), CMV IgG (GD84, Genesis Diagnostics/ ALPCO and ab108724, Abcam), and EBV-VCA (ab108730, Abcam). All HSV-1 IgG-positive samples were screened for HSV2 IgG. Results were determined by comparison with positive, negative, and cutoff controls. Sera with values greater than $10 \%$ of the cutoff control were considered positive. Sera was assayed and analyzed with masked case/control designation.

\section{Statistical analysis}

Statistical analyses were performed using STATA/GraphPad. Missing variables were excluded from analysis. The Fisher exact test was used to compare categorical variables, with a significance level of 0.05 . Continuous variables were analyzed using the Wilcoxon rank-sum test. Data from cohort combination are presented as a Mantel-Haenszel-adjusted OR.

\section{Results}

\section{Higher prevalence of HSV-1 seropositivity in anti-NMDARE cases}

\section{Philadelphia cohort}

A significantly higher number of anti-NMDARE cases had IgG antibodies against HSV-1 (44\%; 7/16) compared with age-matched controls $(14 \% ; 6 / 42)$, leading to an OR of 4.66 (95\% CI 1.3-17.3, $p=0.031$ ) (figure). The mean age of antiHSV-1 IgG-positive and -negative participants was not significantly different.

\section{Barcelona cohort}

Compared with age-matched controls, a higher number of anti-NMDARE cases had IgG antibodies against HSV-1. Fifty-two percent (12/23) of cases had HSV-1 IgG antibodies, 
Table Descriptive statistics for Philadelphia and Barcelona cohorts

\begin{tabular}{|c|c|c|c|c|c|c|c|c|}
\hline & \multicolumn{4}{|c|}{ Philadelphia } & \multicolumn{4}{|l|}{ Barcelona } \\
\hline & Control & Index & Total & $p$ & Control & Index & Total & $p$ \\
\hline \multicolumn{9}{|l|}{ Sex } \\
\hline Female (N) & 17 & 8 & 25 & & 17 & 13 & 30 & \\
\hline Female (\%) & 43.6 & 50.0 & 45.5 & 0.772 & 65.4 & 56.5 & 61.2 & 0.407 \\
\hline Unknown (N) & 1 & 0 & 1 & & 4 & 6 & 10 & \\
\hline \multicolumn{9}{|l|}{ Age } \\
\hline Mean \pm SD, y & $7.9 \pm 2.5$ & $6.8 \pm 3.1$ & $7.6 \pm 2.7$ & 0.242 & $10.4 \pm 5.1$ & $10.6 \pm 5.0$ & $10.5 \pm 5.0$ & 0.888 \\
\hline Median, y (Q1, Q3) & $8(7,10)$ & $7.5(3.8,9)$ & $8(6,10)$ & & $12.5(5.5,15)$ & $12(6,15)$ & $12(5,15)$ & \\
\hline \multicolumn{9}{|c|}{ Clinical measures; patients presenting with $\mathbf{N}(\%)$} \\
\hline Pleocytosis & $8(14.5)$ & $7(43.8)$ & $15(27.3)$ & 0.163 & $5(19.2)$ & $9(39.1)$ & $14(28.6)$ & 0.080 \\
\hline Unknown/unavailable cell count & $17(30.9)$ & $5(31.3)$ & $22(40.0)$ & & $7(26.9)$ & $8(34.8)$ & $15(30.6)$ & \\
\hline Abnormal MRI & $8(14.5)$ & $4(25.0)$ & $12(21.8)$ & 0.441 & $3(11.5)$ & $2(8.7)$ & $5(10.2)$ & 0.999 \\
\hline Unknown/unavailable MRI & $24(61.5)$ & $4(25.0)$ & $28(50.9)$ & & $15(30.8)$ & $13(34.8)$ & $28(32.7)$ & \\
\hline Seizures & $16(41.0)$ & $12(75.0)$ & $28(50.9)$ & 0.037 & $4(15.4)$ & $12(52.2)$ & $16(32.7)$ & 0.013 \\
\hline Encephalopathy & $25(64.1)$ & 15 (93.8) & $40(72.7)$ & 0.043 & $20(76.9)$ & $17(73.9)$ & $37(75.5)$ & 0.999 \\
\hline Movement disorder & $21(53.8)$ & $14(87.5)$ & 35 (63.6) & 0.029 & $16(61.5)$ & $13(56.5)$ & $29(59.2)$ & 0.777 \\
\hline
\end{tabular}

Data are presented as number of participants and frequency (\%). $p$ values are reported from the Fisher exact test, except age, which is reported from the Wilcoxon rank-sum test.

whereas $31 \%(8 / 26)$ of controls were HSV-1 IgG positive (OR 2.46, 95\% CI 0.8-7.9, $p=0.155$ ) (figure). Although there was no statistical difference, the trend in this cohort matches that of the Philadelphia cohort.

\section{Overall}

Combination of the 2 cohorts reveals that an overall 19 (49\%) of 39 anti-NMDARE cases were seropositive for HSV-1 IgG (figure), significantly higher than age-matched controls (14/68 [21\%], Mantel-Haenszel-adjusted OR 3.21, 95\% CI $1.3-7.7, p=0.007)$. The mean age of HSV-1 IgG-positive and -negative participants was not significantly different.

To control for the possibility that nonspecific antibody elevation in case sera could yield false positives on ELISA, we also tested for immunoreactivity to cytomegalovirus (CMV) and Epstein-Barr virus (EBV), infections without known anti-NMDARE association. CMV and EBV-VCA IgG seropositivity did not differ between anti-NMDARE cases and controls in either cohort, although the number of participants positive for CMV and EBV-VCA IgG antibodies was higher in the Barcelona cohort than that in the Philadelphia cohort (Philadelphia-CMV: 5/15 [33\%], EBV: 9/16 [30\%]; Barcelona-CMV: 14/18 [78\%], EBV: 18/22 [82\%]) (figure; Philadelphia-CMV: OR 1.2, 95\% CI 0.32-4.05, $p=0.823$, EBV: OR $1.0,95 \%$ CI $0.3-3.2, p=0.999$; Barcelona-CMV: OR 1.6, 95\% CI 0.39-6.24, $p=0.532$, EBV: OR 1.8, 95\% CI 0.4-7.0, $p=0.505$ ).

\section{Discussion}

In this study, anti-NMDARE cases had a higher prevalence of HSV-1 IgG antibodies than age-matched controls in two separate cohorts. Antibodies to unrelated viruses (CMV and EBV-VCA) were not elevated in anti-NMDARE participants, suggesting that this finding is selective for HSV-1. HSV-1 IgG seroprevalence is greater than $60 \%$ by mid-adulthood. ${ }^{6}$ Therefore, we evaluated the association between HSV-1 infection and anti-NMDARE in children, in which reported HSV-1 IgG seroprevalence is only $26 \%$ at age 7 years. ${ }^{7}$ The rate of positive HSV-1 IgG antibodies detected in our participants with anti-NMDARE is elevated compared with this population statistic and the age-matched control group described here. In this retrospective study, with limited demographic information available, we were unable to control for race or socioeconomic status. However, HSV-1 seropositivity in anti-NMDARE participants was greater than that reported for any demographic group in this age range. ${ }^{7}$ Prospective studies may better control for demographic factors to confirm this finding.

The development of anti-NMDAR immunoreactivity following HSV encephalitis has been hypothesized to result from HSV-mediated brain injury that exposes NMDARs to the immune system, triggering an immune response. ${ }^{4}$ However, none of our anti-NMDARE participants with HSV antibodies had clinically evident HSV encephalitis. The present data 
Figure Seropositivity for IgG against HSV-1, CMV, and EBV

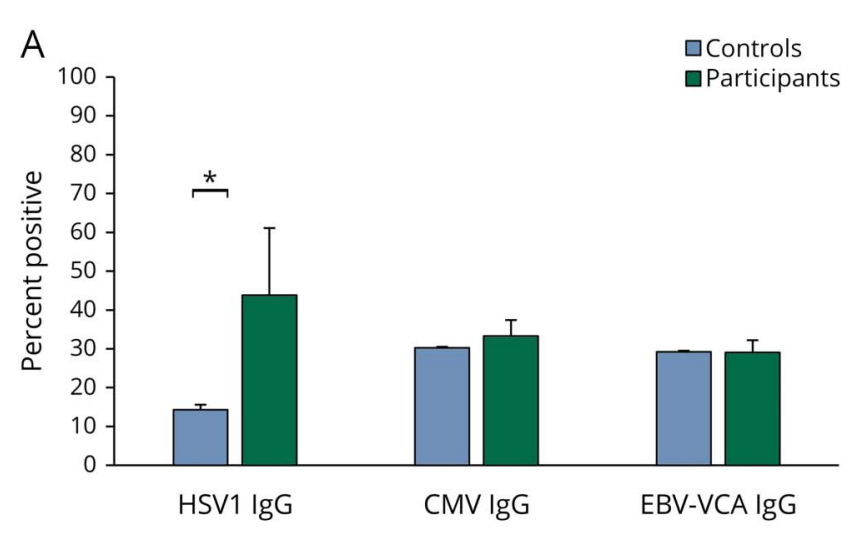

B

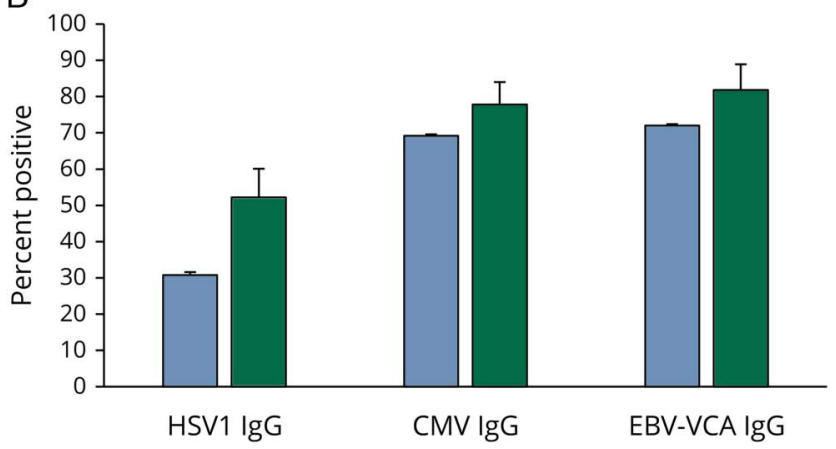

C

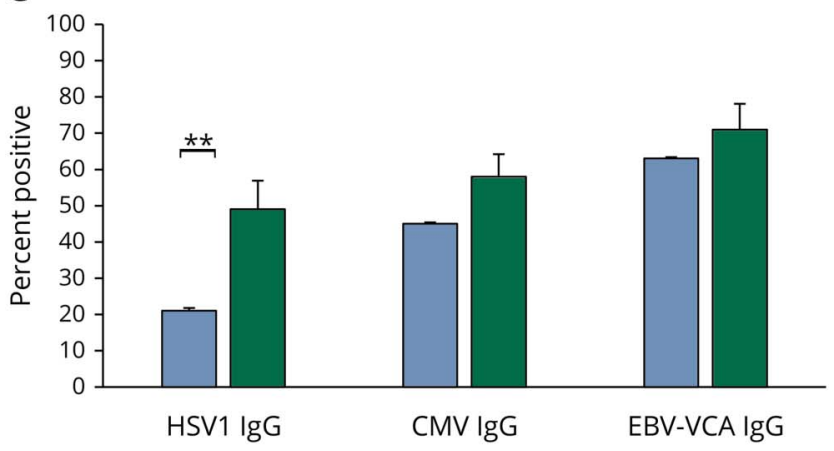

Samples from anti-NMDARE cases or controls from 2 cohorts were tested via ELISA for immunoreactivity to viral antigens. Samples were tested for IgG antibodies to HSV-1 and, as a control, IgG antibodies to CMV and EBV-VCA. (A) In 1 cohort from the neuroimmune repositories at the Children's Hospital of Philadelphia and the University of Pennsylvania, 44\% of anti-NMDARE cases were seropositive for HSV-1 IgG compared with 14\% of age-matched controls $(p=0.031$, Fisher exact test). There was no difference in IgG positivity between cases and controls for either CMV (33\% cases and 30\% controls) or EBV-VCA ( $29 \%$ cases and $29 \%$ controls). Data are presented as percent positive samples with error bars indicating $95 \%$ Cls. (B) In a second cohort from the University of Barcelona, anti-NMDARE cases were more likely to be HSV-1 IgG positive (52\% of anti-NMDARE cases compared with 31\% of age-matched controls, $p=0.155$, Fisher exact test). There was no difference in IgG positivity between cases and controls for either CMV (78\% cases and $69 \%$ controls) or EBV-VCA ( $82 \%$ cases and $72 \%$ controls). (C) Overall, when the cohorts are combined together, anti-NMDARE cases were significantly more likely to be HSV-1 IgG seropositive ( $49 \%$ of anti-NMDARE cases compared with $21 \%$ of age-matched controls, $p=0.007$ ). There was no difference in IgG positivity between cases and controls for either CMV (58\% cases and 45\% controls) or EBV-VCA (71\% cases and $63 \%$ controls). ${ }^{*} p<0.05 ;{ }^{*} p<0.01$. CMV = cytomegalovirus; EBV $=$ Epstein-Barr virus; HSV = herpes simplex virus; NMDARE = NMDA receptor encephalitis; VCA = viral capsid antigen.

suggest an alternate disease mechanism, such as molecular mimicry, in which an epitope expressed by HSV is structurally similar to a portion of the NMDAR. Shared epitopes between
HSV-1 and disease specific autoantigens have been implicated in neuroimmune conditions including myasthenia gravis. ${ }^{8}$ Alternatively, HSV infection may alter NMDAR expression, even outside the CNS, in a way that makes the receptor more immunogenic. For example, HSV-1 has been reported to "disarm" the unfolded protein response. Increased expression of misfolded proteins may result in recognition by autoreactive immune cells. ${ }^{10}$ Finally, HSV-1 could modulate the immune system in a manner that allows inappropriate recognition of native NMDARs.

The present data suggest that nonencephalitic HSV-1 infection may trigger the subsequent development of anti-NMDARE. Prospective studies are needed to determine the timing of antiNMDARE onset after nonencephalitic HSV-1 infection, along with mechanistic studies evaluating the mechanism by which such events are involved in disease pathogenesis.

\section{Author contributions}

Amy Salovin: study concept and design, acquisition of data, analysis and interpretation of data, and manuscript preparation. Jason Glanzman, Kylie Roslin, and Thais Armangue: acquisition of data and analysis and interpretation of data. David R. Lynch and Jessica A. Panzer: study concept and design, analysis and interpretation of data, study supervision, and critical revision of the manuscript for intellectual content.

\section{Acknowledgment}

The authors thank Dr. Josep Dalmau (University Pennsylvania and University Barcelona) for his critical review of the manuscript and the Children's Hospital of Philadelphia Biostatistics and Data Management Core for statistical consultation.

\section{Study funding}

Study funded by the NIH (R21NS088148-01-02).

\section{Disclosure}

A. Salovin, J. Glanzman, and K. Roslin report no disclosures. T. Armangue received research support from the Mutua Madrileña Foundation. D.R. Lynch is an associate editor of the Journal of Neurogenetics; holds a patent for creation of test for anti-NMDA receptor encephalitis; consulted for Bracket Incorporated; and received research support from Edison Pharmaceutical, Shire Pharmaceutical, Reata Pharmaceutical, Horizon Pharma, and the NIH. J.A. Panzer is deceased (no disclosures are included for this author). Full disclosure form information provided by the authors is available with the full text of this article at Neurology.org/NN.

Received December 27, 2017. Accepted in final form February 26, 2018.

\section{References}

1. Dalmau J, Gleichman AJ, Hughes EG, et al. Anti-NMDA-receptor encephalitis: case series and anlysis of the effects of antibodies. Lancet Neurol 2008;7:1091-1098.

2. Gable MS, Sheriff H, Dalmau J, Tilley DH, Glaser CA. The frequency of autoimmune $\mathrm{N}$-methyl-D-aspartate receptor encephalitis surpasses that of individual viral etiologies in young individuals enrolled in the California encephalitis project. Clin Infect Dis 2012;54:899-904. 
Titulaer MJ, McCracken L, Gabilondo I, et al. Treatment and prognostic factors for long-term outcome in patients with anti-NMDA receptor encephalitis: an observational cohort study. Lancet Neurol 2013;12:157-165.

4. Armangue T, Leypoldt F, Málaga I, et al. Herpes simplex virus encephalitis is a trigger of brain autoimmunity. Ann Neurol 2014;75:317-323.

5. Mohammad SS, Sinclair K, Pillai S, et al. Herpes simplex encephalitis relapse with chorea is associated with autoantibodies to N-Methyl-D-aspartate receptor or dopamine-2 receptor. Mov Disord 2014;29:117-122.

6. Xu F, Sternberg MR, Kottiri BJ, et al. Trends in herpes simplex virus type 1 and type 2 seroprevalence in the United States. JAMA 2006;296:964-973.
7. $\mathrm{Xu} \mathrm{F}$, Lee F, Morrow R. Seroprevalence of herpes simplex virus type 1 in children in the United States. J Pediatr 2007;151:374-377.

8. Schwimmbeck PL, Dyrberg T, Drachman DB, Oldstone MBA. Molecular mimicry and myasthenia gravis. An autoantigenic site of the acetylcholine receptor alphasubunit that has biologic activity and reacts immunochemically with herpes simplex virus. J Clin Invest 1989;84:1174-1180.

9. Burnett HF, Audas TE, Liang G, Lu RR. Herpes simplex virus-1 disarms the unfolded protein response in the early stages of infection. Cell Stress Chaperones 2012;17:473-483.

10. Todd DJ, Lee AH, Glimcher LH. The endoplasmic reticulum stress response in immunity and autoimmunity. Nat Rev Immunol 2008;8:663-674. 


\title{
Neurology \\ Neuroimmunology \& Neuroinflammation
}

\author{
Anti-NMDA receptor encephalitis and nonencephalitic HSV-1 infection \\ Amy Salovin, Jason Glanzman, Kylie Roslin, et al. \\ Neurol Neuroimmunol Neuroinflamm 2018;5; \\ DOI 10.1212/NXI.0000000000000458
}

This information is current as of April 5, 2018

\section{Updated Information \& Services}

References

Citations

Subspecialty Collections

Permissions \& Licensing

Reprints including high resolution figures, can be found at:

http://nn.neurology.org/content/5/4/e458.full.html

This article cites 10 articles, 0 of which you can access for free at: http://nn.neurology.org/content/5/4/e458.full.html\#\#ref-list-1

This article has been cited by 5 HighWire-hosted articles: http://nn.neurology.org/content/5/4/e458.full.html\#\#otherarticles

This article, along with others on similar topics, appears in the following collection(s):

Viral infections

http://nn.neurology.org//cgi/collection/viral_infections

Information about reproducing this article in parts (figures,tables) or in its entirety can be found online at:

http://nn.neurology.org/misc/about.xhtml\#permissions

Information about ordering reprints can be found online: http://nn.neurology.org/misc/addir.xhtml\#reprintsus

Neurol Neuroimmunol Neuroinflamm is an official journal of the American Academy of Neurology.

Published since April 2014, it is an open-access, online-only, continuous publication journal. Copyright

Copyright (C) 2018 The Author(s). Published by Wolters Kluwer Health, Inc. on behalf of the American

Academy of Neurology.. All rights reserved. Online ISSN: 2332-7812.

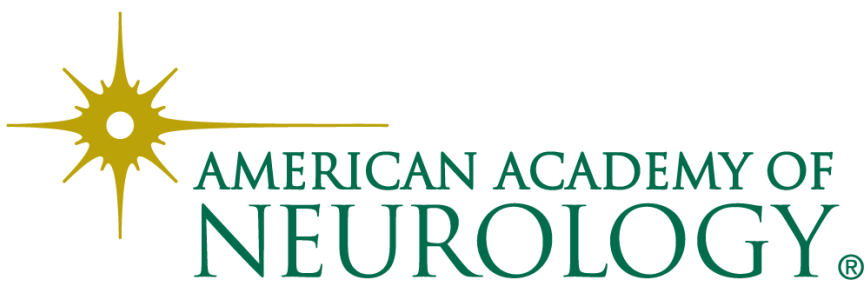

